\section{Speciation and Localization of Arsenic in White and Brown Rice Grains}

\author{
ANDREW A. MEHARG, ${ }^{*}{ }^{\dagger}$ ENZO LOMBI, \\ PAUL N. WILLIAMS, ${ }^{\dagger}$ \\ KIRK G. SCHECKEL, ${ }^{\S}$ JOERG FELDMANN, \\ ANDREA RAAB, ${ }^{\triangle}$ YONGGUAN ZHU, ${ }^{\perp}$ AND \\ R A F I Q L I S L A M \# \\ School of Biological Sciences, University of Aberdeen, \\ Cruickshank Boulevard, St Machar Drive, \\ Aberdeen, AB24 3UU, U.K., Plant and Soil Science Laboratory, \\ Department of Agricultural Science, Faculty of Life Science, \\ University of Copenhagen, Thorvaldsensvej 40, \\ 1871 Frederiksberg C, Denmark, National Risk Management \\ Research Laboratory, U.S. Environmental Protection Agency, \\ 5995 Centre Hill Avenue, Cincinnati, Ohio 45224, School of \\ Physical Sciences, University of Aberdeen, Meston Building, \\ Meston Walk, Aberdeen, AB24 3UE, U.K., Research Centre for \\ Eco-environmental Sciences, Chinese Academy of Sciences, \\ Beijing 100085, China, and Department of Soil Science, \\ Bangladesh Agricultural University, \\ Mymensingh 2202, Bangladesh
}

Received September 3, 2007. Revised manuscript received November 30, 2007. Accepted December 03, 2007.

Synchrotron-based X-ray fluorescence (S-XRF) was utilized to locate arsenic (As) in polished (white) and unpolished (brown) rice grains from the United States, China, and Bangladesh. In white rice As was generally dispersed throughout the grain, the bulk of which constitutes the endosperm. In brown rice As was found to be preferentially localized at the surface, in the region corresponding to the pericarp and aleurone layer. Copper, iron, manganese, and zinc localization followed that of arsenic in brown rice, while the location for cadmium and nickel was distinctly different, showing relatively even distribution throughout the endosperm. The localization of As in the outer grain of brown rice was confirmed by laser ablation ICP-MS. Arsenic speciation of all grains using spatially resolved $\mathrm{X}$-ray absorption near edge structure ( $\mu$-XANES) and bulk extraction followed by anion exchange HPLC-ICP-MS revealed the presence of mainly inorganic As and dimethylarsinic acid (DMA). However, the two techniques indicated different proportions of inorganic:organic As species. A wider survey of whole grain speciation of white $(n=39)$ and brown $(n=45)$ rice samples from numerous sources (field collected, supermarket survey, and pot trials) showed that brown rice had a higher proportion of inorganic arsenic present than white rice. Furthermore, the percentage of DMA present in the grain increased along with total grain arsenic.

\footnotetext{
* Corresponding author e-mail: a.meharg@abdn.ac.uk.

${ }^{\dagger}$ School of Biological Sciences, University of Aberdeen.

‡ University of Copenhagen.

${ }^{\S}$ U.S. Environmental Protection Agency.

${ }^{\triangle}$ School of Physical Sciences, University of Aberdeen.

${ }^{\perp}$ Chinese Academy of Sciences.

" Bangladesh Agricultural University.
}

\section{Introduction}

Concerns have been raised regarding the levels of As, a human carcinogen, in rice, with studies showing elevated grain As concentrations in regions where rice paddy fields are irrigated with As contaminated groundwater (1-5), where paddies have become contaminated through base and precious metal mining and industrial activity (6), and through the use of arsenical pesticides $(4,7)$. Variation in natural paddy soil As concentrations may also lead to variation in grain As, though this has not been explored to date. Regardless of how the rice becomes elevated in As, modeling shows that levels of As in rice contribute considerably to dietary intake, especially in regions with subsistence rice diets or for ethnic groups with high dietary rice intake $(2,4,7)$.

Crucial to understanding the risk posed by As in rice is its speciation and location in grain. Ren et al. (8) have shown that As levels in bran from a range of Chinese rice samples were considerably higher compared to those in polished rice, resulting in elevated concentrations in brown rice compared to the white rice counterparts.

Studies where powdered rice grain has been solvent extracted have shown significant differences between SE Asian rice where inorganic As is the dominate species, to U.S./European produced rice which has a much higher proportion of the methylated species dimethylarsinic acid (DMA) (4), with the inorganic species thought to be the most toxic (9). Extraction and chromatography interconvert inorganic species arsenate and arsenite meaning that HPLCICP-MS approaches used to speciate rice cannot accurately determine these species' in vivo concentrations, and thus a total inorganic arsenic figure is given (10). Also, extraction of As from grains is incomplete and consequently a significant part of the total As cannot be speciated using this technique. Furthermore, As(III) species are known to have a high affinity for-SH groups, such as those in proteins and phytochelatins $(11,12)$, and in planta arsenite may be bound to these moieties, and released into solution on extraction and sample oxidation. Harsh chemical extraction may alter mobilization of As(III) from sulfyhydryl coordination in a manner different from what happens naturally in the gut, giving an overestimation of bioavailability.

Here we present the first study using in situ synchrotron $\mathrm{X}$-ray fluorescence (S-XRF) to map element location and $\mu$-Xray absorption near edge spectroscopy ( $\mu$-XANES) to assess As speciation in rice grain. The suitability of XANES to investigate As speciation in biological samples has been previously demonstrated (13). The present work is, to our knowledge, the first to investigate low levels of As using this technique in plant material. In addition to in situ As speciation by $\mu$-XANES, the S-XRF mapping also included the elements iron (Fe), zinc ( $\mathrm{Zn})$, cadmium (Cd), manganese (Mn), copper $(\mathrm{Cu})$, and nickel $(\mathrm{Ni})$ to provide the geochemical framework in which the As was deposited in the grain. This information is also important in terms of nutritional value (i.e., Fe and Zn content) of the grains. S-XRF imaging was complemented by laser ablation ICP-MS. Bulk speciation of a wider survey of white and brown rice expanded the context of these findings to explore the relationship between total As concentration in the grain and arsenic speciation.

\section{Materials and Methods}

Origin of Specimens Used for the Synchrotron Investigation. Four rice samples were obtained from Bangladesh, United States (2 samples), and China. Samples of brown rice with high As were generated in pot experiments conducted 
TABLE 1. Bulk Grain Speciation by HPLC-ICP-MS of Samples Used in XAS Microtomography Studies (Each Sample Analyzed in Duplicate, the Average Value Is Presented)

\begin{tabular}{llcccccccc}
\multicolumn{1}{c}{ origin } & milling & $\begin{array}{c}\text { total As } \\
(\mathbf{m g} / \mathbf{k g})\end{array}$ & $\begin{array}{c}\text { DMA } \\
(\mathbf{m g} / \mathbf{k g})\end{array}$ & $\begin{array}{c}\text { MMA } \\
(\mathbf{m g} / \mathbf{k g})\end{array}$ & $\begin{array}{c}\text { AsIll }+ \text { AsV } \\
(\mathbf{m g} / \mathbf{k g})\end{array}$ & $\begin{array}{c}\mathbf{\Sigma} \text { species } \\
(\mathbf{m g} / \mathbf{k g})\end{array}$ & $\begin{array}{c}\text { non extract. } \\
(\%)\end{array}$ & $\begin{array}{c}\text { organo } \\
\text { As }(\%)\end{array}$ & $\begin{array}{c}\text { inorg. } \\
\text { As }(\%)\end{array}$ \\
Bangladesh & brown & 0.61 & 0.17 & 0.01 & 0.28 & 0.46 & 25 & 28 & 46 \\
China & brown & 0.36 & 0.09 & 0.01 & 0.21 & 0.31 & 14 & 27 \\
U.S. & white & 0.28 & 0.10 & $<$ LOD & 0.11 & 0.21 & 26 & 34 \\
U.S. & brown & 0.44 & 0.14 & 0.01 & 0.17 & 0.32 & 27 & 28 \\
\hline
\end{tabular}

with the long grained cultivar BR29, the most widely utilized in Bangladesh. Rice plants were grown on paddy soil from the nongroundwater irrigated affected area of Myemsingh, Bangladesh, which was irrigated with water containing $2 \mathrm{mg} / \mathrm{L}$ As as sodium arsenate. Two-liter pots were utilized and the plants were grown to maturity outside at Myemsingh during the dry season. Brown rice was also obtained from U.S. and Chinese paddy fields, both of which were long grained. White market rice was obtained, in the UK, from U.S.-imported white long grain rice. The Chinese rice sample was obtained from a mining-contaminated paddy soil from Dabaoshan area in Guangdong province in Southern China. The Dabaoshan mixture metal mine has been in operation more 30 years. Wastewater from the mining operation has been contaminating the nearby paddy soils, where rice grains for this study were taken.

Data and Specimens Used to Assess Correlations between Total As and As Speciation. To assess possible correlations between total As and As speciation in white and brown rice a wider survey was compiled from our existing studies and additional new data. A total of 55 data points were collated from the studies of Williams et al. $(1,4)$ and Liu et al. (15). New samples (26) were obtained from a Bangladesh field survey, and a Japanese supermarket survey was also included in the data set.

Synchrotron-Based Elemental Mapping and Spectroscopy. The rice was bisected along its latitudinal axis, and the half without the germ was analyzed to simplify image interpretation. Microsectioning of rice grains (not embedded in resin) was attempted but was not successful due to the nature of the grains which resulted in pulverization of the sliced sections. Embedding of the grains was not considered since this could have resulted in changes in As speciation. Since determining speciation was one of the main aims of the synchrotron investigation, we decided to use bisected samples. This choice is not ideal in terms of elemental mapping, due to X-ray penetration (see below), but represents the best option to conduct As speciation in situ using XANES because it minimizes the risk of artifacts during sample preparation. Synchrotron-based elemental and image analysis was conducted at Sector 20-ID (PNC/XOR) at the Advanced Photon Source, Argonne National Laboratory. Specific details of the data collection and analysis are given in the Supporting Information (SI).

Total Arsenic Determinations by ICP-MS and Arsenic Speciation by HPLC-ICP-MS. Total As concentrations were determined on ball-milled samples of the grain, subjected to nitric acid/hydrogen peroxide digestion and microwave digestion, including rice flour CRM (NIST Certified Reference Material 1568a Arkansas long grain rice flour) in the sample batch, followed by ICP-MS As quantification, according to procedures detailed in Williams et al. (1). Quality control results were as presented in our previous publications $(4,7)$. Arsenic speciation, using a $2 \mathrm{M}$ trifluoroacetic acid extraction (TFA) followed by TFAHPLC-ICP-MS, and quality control procedures were identical to those presented previously (4).

Laser Ablation ICP-MS (LA-ICP-MS). The Bangladesh rice sample had the highest total As concentration (Table 1) and, therefore, it was selected for analysis with LA-ICP-MS to complement the S-XRF data. Because in this case As speciation was not the object of the investigation, grains were embedded in resin used for preparation of pathological samples and then the block was sectioned and polished. Specific details of the data collection and analysis are given in the SI.

\section{Results and Discussion}

Bulk Arsenic Concentration and Speciation in Rice Used for XAS Study. Total As concentrations in all 4 samples, ranging from 0.28 to $0.61 \mathrm{mg} / \mathrm{kg}$ As (Table 1), were high with respect to typical rice grain background levels of $0.05-0.15$ $\mathrm{mg} / \mathrm{kg}(1,4,7)$. The inorganic As content of the rice varied from 39 to $57 \%$ of the total and the nonextractable As ranged from 14 to $27 \%$ (Table 1). The Bangladesh specimen was specifically experimentally contaminated, while all other samples were meant for human consumption.

Arsenic Localization in Grain. Interpretation of the elemental distribution maps has to take into account the fact that the images are projections of all of the element present in the sample in the specific path of the beam. Areas within the grain which are of higher density or thickness will provide a stronger XRF signal $(14,15)$. In other words, S-XRF imaging compresses $3 \mathrm{D}$ information into $2 \mathrm{D}$ and this must been born in mind when viewing the data. As explained above, thin sections could not be prepared without embedding the samples in resin and we opted against this option to preserve As speciation for $\mu$-XANES analysis. However, if these limitations are considered during data interpretation it is still possible to ascertain important information regarding elemental distribution.

$\mathrm{S}$-XRF revealed strong As localization within the rice grain. Considering first the brown rice sample from Bangladesh, the image looking directly face on to a latitudinal section in the germ-free half of the grain, Figure 1, shows very strong As location at the top of the image, concurrent with Fe, $\mathrm{Zn}$, $\mathrm{Mn}$, and $\mathrm{Cu}$ with an additional fanning out of all these elements corresponding to the surface of the grain. An expanded section of the edge image of a second Bangladesh rice grain (SI, Figure 1) confirms that As is highly localized at the surface of the grain. The pattern of As localization in this more detailed scan followed that of $\mathrm{Cu}, \mathrm{Fe}, \mathrm{Mn}$, and $\mathrm{Zn}$, but not of Cd or Ni.

Complete scans of brown rice, again from Bangladesh (Figure 1), from China (SI Figure 2) and the U.S. (SI Figure 3) all show this strong localization of $\mathrm{As}, \mathrm{Cu}, \mathrm{Fe}$, and $\mathrm{Zn}$, but not $\mathrm{Ni}$ or $\mathrm{Cd}$, in the outer layers of the grain.

The outer part of brown rice is constituted by the pericarp and the aleurone layer, living cells rich in lipid and protein. The aleurone layer surrounds the starchy endosperm (16). The pericarp and most of the aleurone layer is removed during polishing, giving bran, leaving the subaleurone and endosperm remaining in white rice, as polishing also removes the germ (8). Ren et al. (8) found that there were 6 -fold differences in As concentrations between the bran and milled rice for a range of rice from various locations in China, resulting in higher levels in brown rice compared to milled rice. In the Poaceae, the pericarp and aleurone layer make up about $14 \%$ of the grain (16), and thus, even though the 

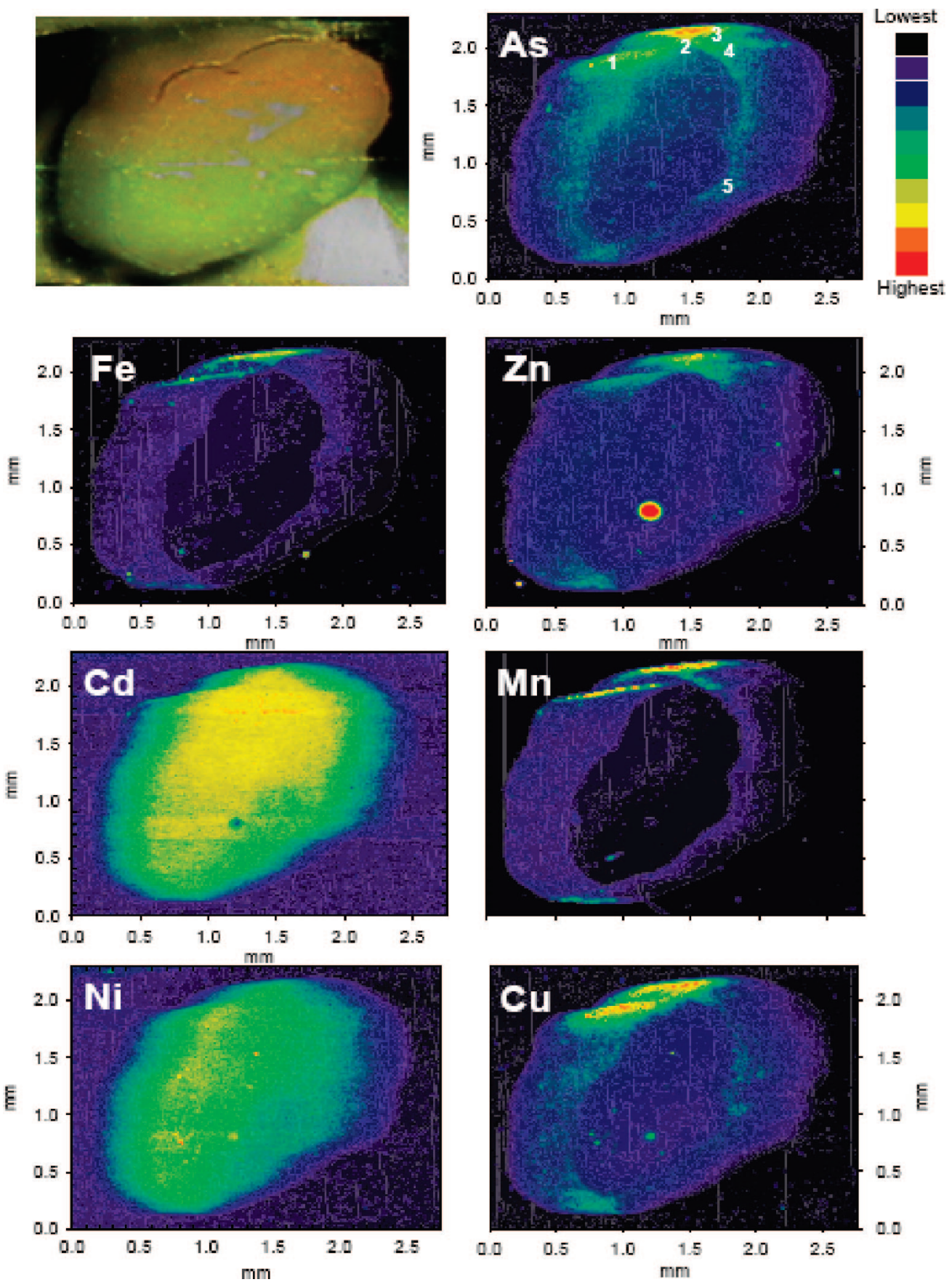

FIGURE 1. S-XRF elemental maps of the Bangladesh brown rice sample. The numbers in the As map refer to the positions where $\mu$-XANES spectra were collected (these spectra are reported in Figure 4 and their analyses is shown in SI Table 1). The color bar is in arbitrary units with the black and red corresponding to the lowest and highest relative concentrations. XRF signals were collected at $15 \mu \mathrm{m}$ steps.

bran is considerably higher in As than the endosperm, the relative differences between brown and white rice range from 15 to $100 \%$ greater As in brown, compared to $200-600 \%$ differences between bran and white rice (8).

The colocation of $\mathrm{Fe}, \mathrm{Cu}, \mathrm{Mn}$, and $\mathrm{Zn}$ with As in the aleurone layer is consistent with similar comparison in the levels of these metals between bran and white rice (8). Also, a number of microprobe studies on element location in grain, including rice $(17,18)$, and other members of the Poaceae grain utilized for food (19-21) have shown strong localization of cations in the aleurone, with most studies focusing on $\mathrm{Zn}$. These studies also observed similar localization in the germ of $\mathrm{Zn}$ and other cations. We did not concentrate on the germ in this study, but the findings presented here suggest that the germ should also be included in the focus of future studies.
From all the scans of brown rice (Figure 1; SI Figures 1 and 4) it is observed that As and the other codepositing elements $\mathrm{Cu}, \mathrm{Fe}, \mathrm{Mn}$, and $\mathrm{Zn}$, are not uniformly coated around the grain, but are centered along the surface longitudinal groove. This is clearer in the off-center aligned grains (Figure 1; SI Figures 2 and 3). To our knowledge, this elemental location along longitudinal grooves has not been previously illustrated.

The localization of As at the surface of brown rice grain was further demonstrated for the Bangladesh rice sample in latitudinal section using LA-ICP-MS (Figure 2). The spatial resolution of LA-ICP-MS is considerably lower than that of $\mathrm{S}-\mathrm{XRF}$, and like $\mathrm{S}-\mathrm{XRF}$ it is a semiquantitative technique with respect to totals analysis, enabling relative differences in concentrations to be ascertained. Also, the LA data is truly 


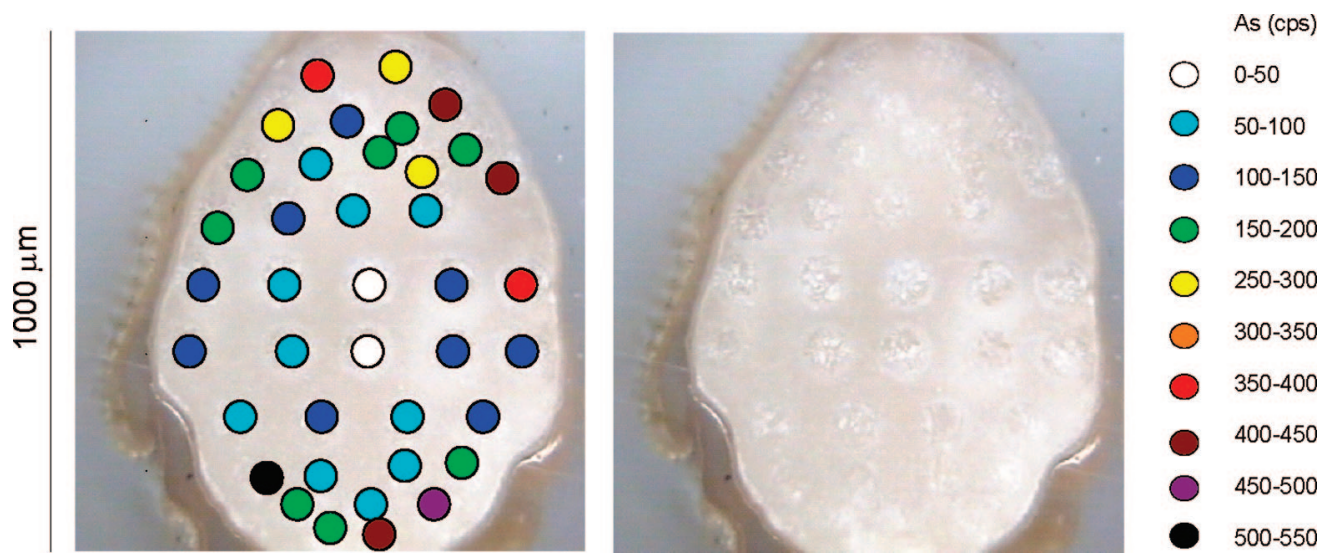

FIGURE 2. Laser ablation ICP-MS of the Bangladesh rice sample used in Figure 1, and SI Figure 1 and 4. Counts per second (CPS) recorded for each ablation are color graded. Total carbon was also checked and this was uniform across the grain, showing that the amount of sample ablated at each location was equivalent.

2D, and confirms that interpretation that As is more concentrated in epidermal layers for the S-XRF scans, where $3 \mathrm{D}$ data are compressed into $2 \mathrm{D}$, is correct.

For the white rice sample (Figure 3 ) the localization pattern of As is entirely different from that of brown rice. Since the As-rich external parts of the grain (pericarp and most of the aleurone) are removed during polishing, the As distribution in white rice appears relatively even throughout the grain. This indicates that As is evenly distributed across the endosperm. The apparent sharp gradient in the relative As concentration from the edge to the center of the grain is due to the depth of grain scanned at each pixel. Copper, Mn, Fe, and $\mathrm{Zn}$ distributions are patchy as a result of a weak XRF signal once the metal-rich external part of the grain is removed by polishing. These findings also indicate that the removal of the pericarp and aleurone layer during polishing reduce the nutritional value of rice in terms of $\mathrm{Fe}$ and $\mathrm{Zn}$ content.

Cadmium and Ni show uniform distribution in both white (Figure 4) and brown rice (Figure 1; SI Figures 1 and 4). Moriyama et al. (22) showed that when rice was polished, Cd concentrations only fell by $3 \%$, suggesting that this element is mainly localized in the endosperm. The pattern of distribution for arsenic in white rice was similar to that for $\mathrm{Cd}$ and Ni indicating that, once the As-rich pericarp and aleurone layer are removed, the remaining As is distributed homogeneously in the white rice grain.

The preferential localization of As in the aleurone layer provides clues as to why As is deposited in the grain. The aleurone is composed of phytic acid (inositol hexaphosphate) rich granules, also rich in $\mathrm{Ca}, \mathrm{Mg}, \mathrm{K}$, and $\mathrm{Zn}$, and is thought to be a storage reservoir for these metals and $\mathrm{P}$ (from the phytic acid) for when the seed germinates and grows (17-22). The aleurone layer forms about 7-9 days after flowering in rice, differentiating from the starchy endosperm and outer pericarp (17). Microprobe studies have shown at this stage that $\mathrm{Mg}, \mathrm{P}$, and $\mathrm{K}$ were evenly distributed throughout the grain at this time period, but by day $12 \mathrm{Mg}$ and $\mathrm{P}$ started to stratify, concentrating in the aleurone (17). By 28 days after flowering, all three elements were highly concentrated in the aleurone. A time course of total concentrations of these nutrients in rice for the same study showed 2 orders of magnitude increase in concentrations over this time period, indicating active export to the grain over this time period. This suggests that these elements are being directly deposited in the aleurone during filling, rather than redistribution from the endosperm. While the equivalent experiments have to be conducted for As and, indeed, this must be a priority for future research, the pattern of codeposition in the aleurone may suggest that most As is exported to the grain during days 10-20 from flowering (17). This information could be essential for regulating As off-take into rice grain. Since As is mobilized under aerobic conditions $(23,24)$, timing of paddy soil draining could potentially greatly alter As grain export, though this would depend on rapid translocation of recently root-assimilated As to the grain. In contrast, if grain As is mobilized from shoot reserves, altering As assimilation at or around flowering may have negligible impact. Thus, understanding the dynamics of As uptake into shoot is also a research priority.

Speciation of As Using $\boldsymbol{\mu}$-XANES. The As K-edge spectra of the standard compounds are reported in Figure 4. The peaks of the absorption edge (white line) energies increased in the order As $(\mathrm{Glu})_{3}<$ arsenite $<\mathrm{DMA}<\mathrm{MMA}<$ arsenate. The position of the primary XANES peak for the different standard compunds, as well as the energy shift between the white lines of arsenite and arsenate $(4 \mathrm{eV})$, are consistent with the findings of Smith et al. (13).

Selected $\mu$-XANES spectra performed on the grain samples are reported in Figure 4 and show that good quality spectra could be collected despite the low average concentration of As in the grains. Generally a mixture of As(III) and As(V) can be inferred by the presence of two main peaks in the spectra. A few $\mu$-XANES spectra collected from brown rice samples (B5, C1, and USb1, Figure 4) were characterized by an adsorption edge occurring at a slightly lower energy than arsenite. This may be due to the presence of S-As compounds (13) but, in general, the $\mu$-XANES spectra do not indicate the presence of significant amounts of these complexes. This is somehow surprising since the aleurone layer, unlike the starchy endosperm, is protein rich (15) and As(III) has high affinity for protein and nonprotein (i.e., phytochelatin and glutathione) - $\mathrm{SH}$ functional group.

PCA analyses were conducted on the whole spectra data set. The indicator value (IND) was used to assess the number of principal components that could accurately describe the system (25). This value is at its minimum when the optimal number of components is reached. In this case IND was minimal with 4 components. However, plotting of the individual components indicated that the fourth component (explaining less that $1 \%$ of the variance) contained essentially noise. The first 3 components could explain $97 \%$ of the variance. Consequently, further analyses were conducted considering the system as a 3-component system.

The choice of standards to be considered for LCF was based on target transformation (TT) of the spectra and the SPOIL value as described by Manceau et al. (26). TT showed that arsenite, arsenate, and DMA had a SPOIL value $<3$ while the SPOIL values for MMA and As(Glu) 3 were $>5$. The SPOIL value for an excellent target typically ranges from 0 to 1.5 

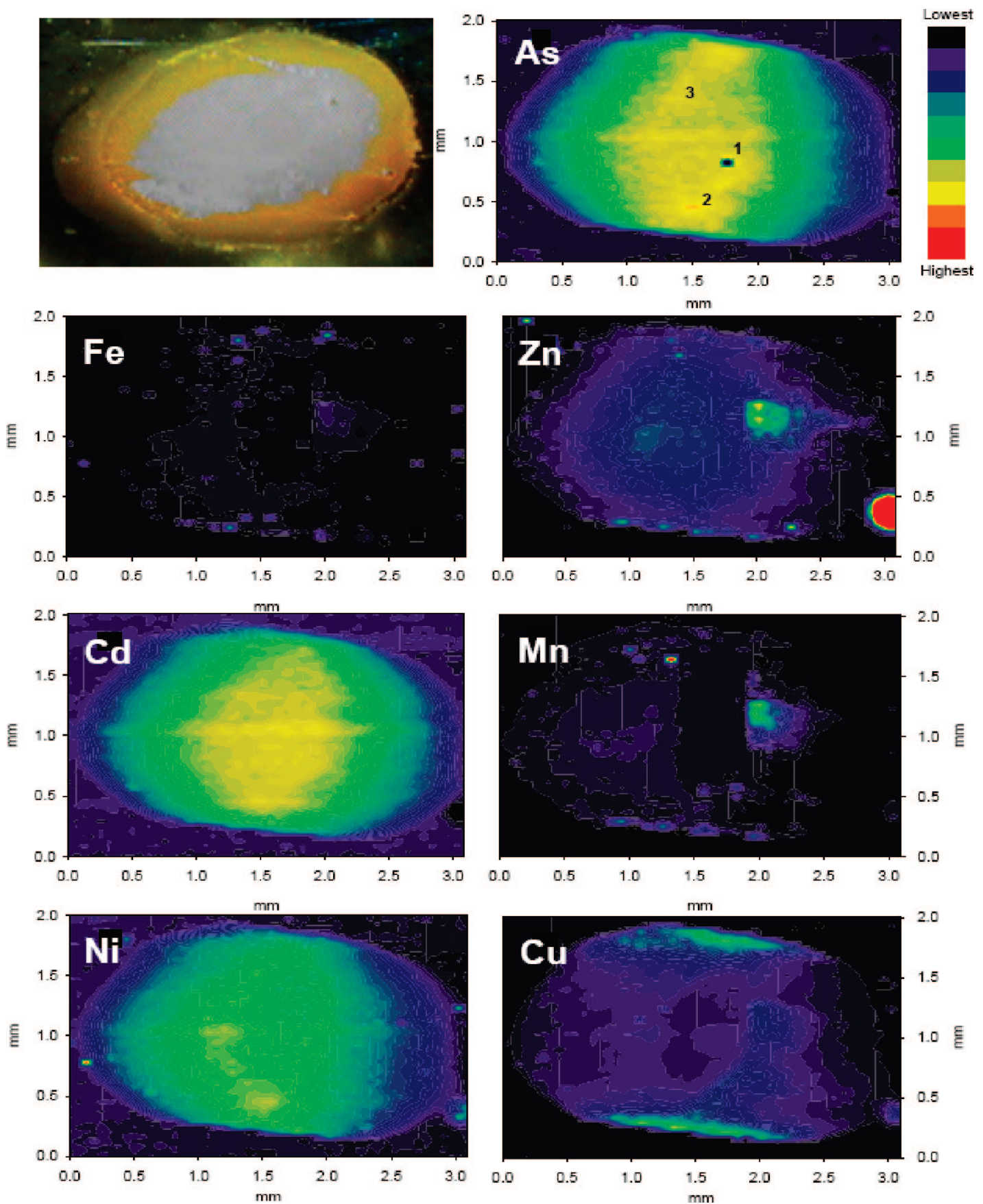

FIGURE 3. S-XRF elemental maps of the U.S. white rice sample. The numbers in the As map refer to the positions where $\mu$-XANES spectra were collected (these spectra are reported in Figure 4 and their analysis is shown in SI Table 1). The color bar is in arbitrary units with the black and red corresponding to the lowest and highest relative concentrations. XRF signals were collected at $15 \mu \mathrm{m}$ steps.

and for a good target ranges from 1.5 to 3 (26). These results are in agreement with the HPLC-ICP-MS speciation of the grains used for the synchrotron investigation (Table 1) which showed inorganic As and DMA to be the dominant species present in the extracts.

Based on the results of the PCA and TT discussed above, LCF was performed using every possible combination of the arsenite, arsenate, and DMA spectra. The goodness of fit $\left(\chi^{2}\right)$ of the LCF and the proportion of each As species (in \%) for all the $\mu$-XANES spectra collected are reported in SI Table 1. The goodness of fit was generally $<1$ with only one spectra from the U.S. white rice (USwl) showing a large $\chi^{2}$. This sample was the only one dominated by $\mathrm{As}(\mathrm{V})$, in all other cases a mixture of both oxidation species was observed. In all brown rice samples $\mu$-XANES scans of the pericarp/ aleurone layer revealed that $70-80 \%$ of the total As was in the form of inorganic arsenite (SI Table 1). In contrast, in the white rice sample spectra collected in the endosperm region of the grain suggested that arsenite accounted only for about half of the total As (even though if the spectra of sample USw1 is not considered arsenite accounts for approximately $65 \%$ of the total As). This difference between brown and white rice, if confirmed, would be important in terms of As bioavailability, and further studies are planned using "bulk" XANES to address this issue (see below).

The proportion of inorganic As determined by $\mu$-XANES, both in brown and white rice, is larger than that assessed using HPLC-ICP-MS (compare Table 1 and SI Table 1). This may be due to two main reasons. First, spectra were collected at microspots in regions of the grain with highest As levels, 


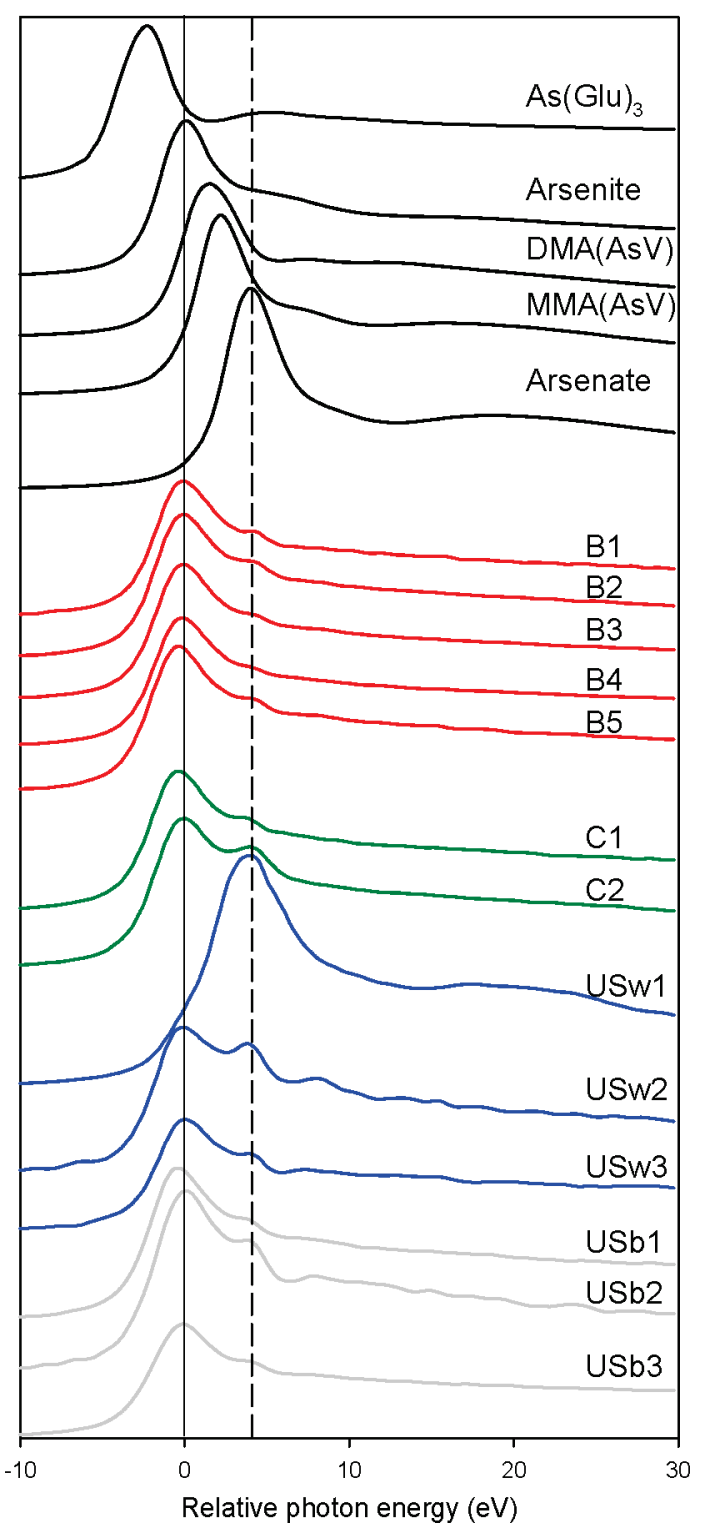

FIGURE 4. Arsenic XANES spectra for selected arsenic species and As $\mu$-XANES spectra from white and brown rice samples. The nomenclature of the spectra of the rice samples is the same as in SI Table 1: B, Bangladesh rice (brown); C, Chinese rice (brown); USw and USb rice from the United States (white and brown, respectively). The numbers after B, C, USw, and USb refer to the position where the spectra were collected (see Figures 1 and 3 and SI Figures 2 and 3). The energy scale is normalized to the white line of arsenite.

that is the aleurone layer in the case of brown rice, so as to maximize resolution given that arsenic levels were low. However, this may not represent the overall As speciation of the grain. The second reason may be related to the incomplete extraction of As by the 2 M TFA extraction used in this study. In fact, $14-27 \%$ of the total As was not extracted by TFA. Comparison of the $\mu$-XANES and HPLC-ICP-MS results could indicate that the non-TFA-extractable As is in the form of inorganic As. This is supported by the findings of Mir et al. (27) who reported that the As species in plant residual, after a methanol and $\mathrm{HCl}$ extraction, were substantially different from those extracted. Even thought Mir et al. (27) did not identify the As species in the plant residuals, it is likely that they were in the form of oxidized inorganic species since their absorption spectra were shifted to energies higher than that of arsenate. We plan to further investigate both these
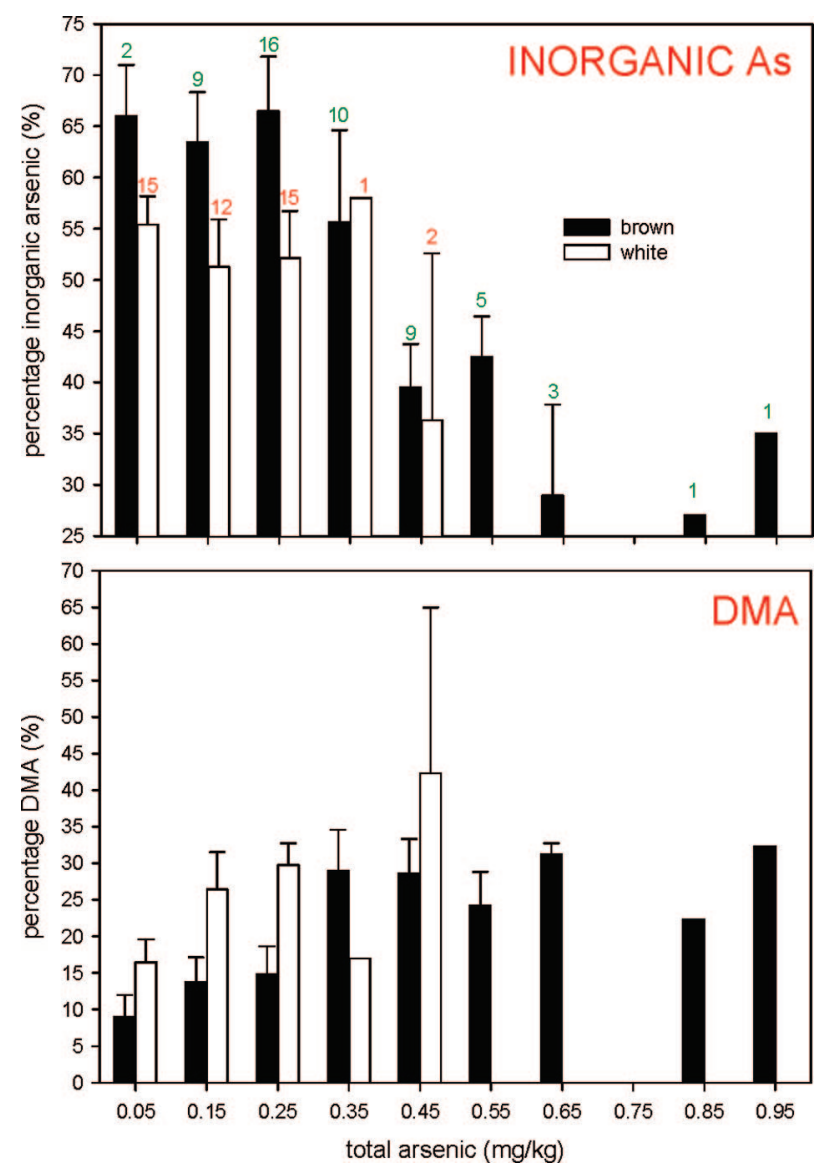

FIGURE 5. Bulk speciation in brown (filled bars) and white (open bars) rice by HPLC-ICP-MS for inorganic arsenic and DMA. Numbers above the bars denote $\mathbf{N}$.

aspects using "bulk" XANES of brown rice and paired samples of the same rice after polishing.

Relationship between Total Grain Arsenic and Speciation between White and Brown Rice. Bulk speciation (i.e., TFA extraction of ball-milled grain), representing the most comprehensive data set, to our knowledge, published to date, showed differences in the pattern of arsenic speciation between brown and white rice (Figure 5). For "normal" levels of As found in rice surveys $(0-0.3 \mathrm{mg} / \mathrm{kg}$ d.wt.) $(1,4,7)$ brown rice had $10 \%$ higher levels of inorganic As than white rice, with the percentages being $\sim 65$ and $55 \%$, respectively. This confirms the S-XRF data that enhanced inorganic levels should be present in brown rice. For brown rice, total As levels rise above this normal range, but still relevant to highly As contaminated soils $(1,4,7)$, the percentage of inorganic arsenic decreases (Figure 5). For DMA, its content increases systematically from 0.05 to $0.25 \mathrm{mg} / \mathrm{kg}$ total arsenic for both brown and white rice, with white rice having higher levels of DMA. As brown rice concentration increases above 0.25 $\mathrm{mg} / \mathrm{kg}$, DMA content plateaus at $30 \%$ DMA. General Linear Modeling (GLM) ANOVA showed for the relationship between total arsenic and percentage inorganic arsenic that both rice type (brown or white) and total arsenic concentration (entered as a covariate) were significant with $p=0.03$ and $p<0.001$ respectively, with the interaction term being nonsignificant. For the corresponding test for percentage organic (DMA) arsenic, the interaction term was significant, showing that white and brown rice behaved differently.

With respect to the threat that arsenic in rice poses to the human diet, assuming that inorganic arsenic is more problematic than organic (DMA) (7), then polishing rice reduces the total arsenic burden of the grain and its inorganic content. Brown rice is unpopular in subsistence rice diets, 
and tends to be more popular in developed countries as a wholegrain alternative to rice. While this raises concerns about brown rice per se, it is clear that products made from rice bran and germ, such as rice milk and direct consumption of bran and germ as dietary fiber supplements, are of particular concern and need further attention.

\section{Acknowledgments}

The U.S. EPA has not subjected this manuscript to internal policy review. Therefore, the research results presented herein do not necessarily reflect Agency policy. Mention of trade names of commercial products and companies does not constitute endorsement or recommendation for use. This work was performed at XOR (Sector 20), Advanced Photon Source (APS), Argonne National Laboratory. Use of the APS was supported by the U.S. Department of Energy, Office of Science, Office of Basic Energy Sciences, under Contract W-31-109-ENG-38. E.L. was supported by the CSIRO Emerging Science Initiative on Synchrotron Science: Extreme Chemistry and Environmental Science.

\section{Supporting Information Available}

Experimental details, 3 figures, and 1 table. This information is available free of charge via the Internet at http:// pubs.acs.org.

\section{Literature Cited}

(1) Williams, P. N.; Islam, M. R.; Adomako, E. E.; Raab, A.; Hossain, S. A.; Zhu, Y. G.; Feldmann, J.; Meharg, A. A. Increase in rice grain arsenic for regions of Bangladesh irrigating paddies with elevated arsenic in groundwaters. Environ. Sci. Technol. 2006, 40, 4903-4908.

(2) Meharg, A. A.; Rahman, M. Arsenic contamination of Bangladesh paddy field soils: Implications for rice contribution to arsenic consumption. Environ. Sci. Technol. 2003, 37, 229-234.

(3) Duxbury, J. M.; Mayer, A. B.; Lauren, J. G.; Hassan, N. Food chain aspects of arsenic contamination in Bangladesh: Effects on quality and productivity of rice. J. Environ. Sci. Health, A 2003, 38, 61-69.

(4) Williams, P. N.; Price, A. H.; Raab, A.; Hossain, S. A.; Feldmann, J.; Meharg, A. A. Variation in arsenic speciation and concentration in paddy rice related to dietary exposure. Environ. Sci. Technol. 2005, 39, 5531-5540.

(5) Islam, M. R.; Islam, S.; Jahiruddin, M.; Islam, M. A. Effects of irrigation water arsenic in the rice cropping system. J. Bio. Sci. 2004, 4, 542-546.

(6) Liao, X. Y.; Chen, T. B.; Xie, H.; Liu, Y. R. Soil As contamination and its risk assessment in areas near the industrial districts of Chenzhou City, Southern China. Environ. Int. 2005, 31, 791798.

(7) Williams, P. N.; Raab, A.; Feldmann, J.; Meharg, A. A. Market basket survey shows elevated levels of As in South Central U.S. processed rice compared to California: Consequences for human dietary exposure. Environ. Sci. Technol. 2007, 41 (7), 2178-2183.

(8) Ren, X-L.; Liu, Q-L.; Wu, D-X.; Shu, Q-Y. Variations in concentration and distribution of health-related elements affected by environmental and genotypic differences in rice grains. Rice Sci. 2006, 13, 170-178.

(9) Petrick, J. S.; Ayala-Fierro, F.; Cullen, W. R.; Carter, D. E.; Aposhian, H. V. Monomethylarsonous acid (MMA ${ }^{\mathrm{III}}$ ) is more toxic than arsenite in changing human hepatocytes. Toxicol. Appl. Pharmacol. 2000, 163, 203-207.

(10) Abedin, M. J.; Cresser, M. S.; Meharg, A. A.; Feldmann, J.; CotterHowells, J. Arsenic accumulation and metabolism in rice (Oryza sativa L.). Environ. Sci. Technol. 2002, 36, 962-968.

(11) Raab, A.; Feldmann, J.; Meharg, A. A. The nature of arsenic phytochelatins complexes in Holcus lanatus and Pteris cretica. Plant Physiol. 2004, 134, 1113-1122.

(12) Raab, A.; Feldmann, J.; Schat, H.; Meharg, A. A. Uptake, translocation and transformation of arsenate and arsenite in sunflower (Helianthus annuus) - Part I: Formation of arsenicphytochelatin complexes during exposure to high arsenic concentrations. New Phytol. 2005, 168, 551-558.

(13) Smith, P. G.; Koch, I.; Gordon, R. A.; Mandoli, D. F.; Chapman, B. D.; Reimer, K. J. X-ray absorption near-edge structure analysis of arsenic species for application to biological environmental samples. Environ. Sci. Technol. 2005, 39, 248-254.

(14) Scheckel, K. G.; Hamon, R. E.; Jassogne, L.; Rivers, M.; Lombi, E. Synchrotron X-ray Absorption-Edge Computed Microtomography Imaging of Thallium Compartmentalization in Iberis intermedia. Plant Soil 2007, 290, 51-60.

(15) McNear, D. H.; Peltier, E.; Everhart, J.; Chaney, R. L.; Sutton, S.; Newville, M.; Rivers, M.; Sparks, D. L. Application of quantitative fluorescence and absorption-edge computed microtomography to image metal compartmentalization in Alyssum murale. Environ. Sci. Technol. 2005, 39, 2210-2218.

(16) Esau, K. Anatomy of Seed Plants, 2nd ed.; Wiley: New York, 1977.

(17) Ogawa, M.; Tanaka, K.; Kasai, Z. Accumulation of phosphorus, magnesium and potassium in developing rice grains: followed by electron microprobe X-ray analysis focussing on the aleurone layer. Plant Cell Physiol. 1979, 20, 19-27.

(18) Ogawa, M.; Tanaka, K.; Kasai, Z. Energy-dispersive X-ray analysis of phytin glonoids in aleurone particles of developing rice grains. Soil Sci. Plant Nutr. 1979, 25, 437-448.

(19) Orturk, L.; Yazici, M. A.; Yucei, C.; Torun, A.; Cekic, C.; Bagci, A.; Ozkan, H.; Braun, H-J.; Sayers, Z.; Cakmak, I. Concentration and localization of zinc during seed development and germination in wheat. Physiol. Plant. 2006, 128, 144-152.

(20) Lott, J. N. A.; Spitzer, E. X-ray analysis studies of elements stored in protein body globoid crystals of Triticum grains. Plant Physiol. 1980, 66, 494-499.

(21) Mazzolin, A. P.; Pallaghy, C. K.; Legge, G. J. F. Quantitative microanalysis of $\mathrm{Mn}, \mathrm{Zn}$, and other elements in mature wheat seed. New Phytol. 1985, 100, 483-509.

(22) Moriyama, T.; Shindoh, K.; Taguchi, Y.; Watanabe, H.; Yasui, A.; Joh, T. Changes in the cadmium content of rice during the milling process. J. Food Hygien. Soc. Jap. 2003, 44, 145-149.

(23) Meharg, A. A. Arsenic in rice - understanding a new disaster for South-East Asia. Trends Plant Sci 2004, 9, 415-417.

(24) Marin, A. R.; Masscheleyn, P. H.; Patrick, W. H. Soil redox-pH stability of arsenic species and its influence on arsenic uptake by rice. Plant Soil 1993, 152, 1993.

(25) Malinowski, E. R. Factor Analysis in Chemistry; Wiley: New York, 1991.

(26) Manceau, A.; Marcus, M. A.; Tamura, N. Quantitative speciation of heavy metals in soils and sediments by synchrotron X-ray techniques. In Applications of Synchrotron Radiation in LowTemperature Geochemistry and Environmental Science; Fenter, P. A., Rivers, M. L., Sturchio, N. C., Sutton, S. R., Eds.; Mineralogical Society of America: Washington, DC, 2002; Vol. 49, pp 341-428.

(27) Mir, K. A.; Rutter, A.; Koch, I.; Smith, M. P.; Reimer, K. J.; Poland, J. S. Extraction and speciation of arsenic in plants grown on arsenic contaminated soils. Talanta 2007, 72, 1507-1518.

ES702212P 